\title{
Efficacy of Pre-Operative Submucosal Injection of Dexamethasone in Mandibular Third Molar Surgery: A Randomized Control Trial
}

INTRODUCTION: Surgical extraction of third molar irrespective of any technique results in postoperative pain, swelling of face and limited mouth opening. The aim of the present study was to assess and compare the effects of Dexamethasone (4mg) administered prior to surgery.

MATERIALS AND METHOD: A randomized control trial was conducted which included a total of fifty patients. All the patients were randomly put in two groups of twenty five each. Group I patients underwent transalveolar extraction of third molar under local anesthesia and standard oral drug regime. Group II patients received an additional submucosal injection of dexamethasone 4 mg, thirty minutes prior administration of local anaesthesia. Pain, swelling and mouth opening was recorded on second, seventh and tenth post-operative days after surgery.

RESULTS: The difference in pain scores on second post-operative day between two groups were found statistically non-significant. However, there was significant reduction in pain scores on seventh and tenth day in both groups. Mouth opening showed statistically significant difference between the two groups.

CONCLUSION: The observations of the present study provide a fundamental basis for the use of corticosteroids such as dexamethasone sodium phosphate in the form of submucosal administration in lower than usual doses to decrease postoperative inflammation when compare to other routes of drug administration.

KEYWORDS: Corticosteroids, Dexamethasone, Impacted third molar

\section{INTRODUCTION}

In oral cavity, mandibular third molar is one of the commonly impacted tooth. ${ }^{1}$ There are various reasons for impaction of a tooth but the lack or loss of space in the arch is the major cause. ${ }^{2}$ It can be due to combination of genetic and environmental factors resulted in discrepancy in size of tooth and jaw. In most of the cases, impacted mandibular molar are asymptomatic but pathology can develop in some cases. The problems associate with molars can be from simple dental caries to more complex conditions such as formation of cyst or development of malignant lesion in the follicular tissue surrounded by the tooth. ${ }^{3}$ Therefore extraction of impacted third molars is necessary and it is the most common practice in speciality of oral surgery so that prevent the suspected pathology before its arousal. ${ }^{4}$ Surgical extraction of third molar irrespective of any technique results in postoperative pain, swelling of face and limited mouth opening. ${ }^{5}$ There are various measures to alleviate the pain, swelling and trismus which includes application of cold or heat, oral or intravenous non-steroidal anti inflammatory agents (NSAIDs), corticosteroids. ${ }^{6}$

Many researchers suggested use of local injection of steroid to overcome post-operative inflammation of surrounding tissue..$^{7-9}$ However, use of local or systemic steroid have some side-effects such as risk of infection, hyperglycemia and suppression of immune system..$^{10}$ Surgical extraction of impacted molar associates with injury to surrounding soft and bony tissues and may result in pain, swelling and trismus. These symptoms commonly arise after two days of extraction." ${ }^{11}$ The sequel after surgery may hamper the patient's quality of life.

Synthetic corticosteroid, dexamethsone has good anti-inflammatory action. Its potency is 20-30 times when compared to natural corticosteroid. Alexander and Throndson observed use of many combination of Dexamethasone based on past literature. ${ }^{12}$

For many years, oral surgeons administered intravenous corticosteroids preoperatively or just after extraction of third molar in order to decrease inflammation and other associated symptoms of surgery. Various studies have suggested use of NSAIDs drugs is effective for controlling swelling and trismus. ${ }^{13,14}$ The aim of the present study was to assess and compare the effects Dexamethasone (4 
mg) administered prior to surgical third molar surgery.

\section{MATERIALS AND METHOD}

A randomized control trial was conducted which included a total of fifty patients who reported to the Department of Oral and Maxillofacial Surgery in a Dental College \& Hospital, Jaipur, Rajasthan.

\section{Inclusion criteria}

- Patients were 15 to 40 years of age.

- Patients without any significant medical history.

- All patients who have impacted lower third molars undergoing transalveolar extraction of the impacted third molar.

\section{Exclusion Criteria}

- Medically compromised patients

- Pregnant and lactating women were excluded

- Patient who had periapical pathology in the tooth to be extracted

- Patients who had habit of Smoking and consuming alcohol

- Uncooperative patients

Fifty patients who fulfilled the above criteria were included for the study. Informed written consent was taken from patients after explaining the about the procedure and follow up of the study. Intraoral periapical (IOPA) radiograph and Orthopantamogram was taken for all the subjects. Routine blood investigations were carried out. Detail history of patients was taken to rule out use of preoperative antimicrobial, NSAIDs or other drugs that might influence healing and inflammation. All the patients were randomly put in two groups of twenty five each.

Group I patients underwent transalveolar extraction of third molar under local anesthesia and standard oral drug regime. Group II patients received an additional submucosal injection of dexamethasone 4 $\mathrm{mg}$, thirty minutes prior administration of local anaesthesia. All patients were operated by the single oral surgeon and the surgical wound was closed with 3-o silk suture.

Patients were instructed to rinse their mouth with $5 \%$ betadine solution for one minute. An inferior alveolar nerve block, lingual never block and a long buccal nerve block, using $2 \%$ lignocaine hydrochloride with vasoconstrictor [1:200ooo] was administered. Trapezoid flap was made using a fullthickness incision. Periosteal elevator was used to lift the flap. The surrounding bone was trimmed and the tooth was sectioned wherever required by using burs and the impacted third molar was extracted with the help of forceps and elevators. Patients were examined for the symptoms pain, swelling and trismus, preoperatively and on the second, seventh, tenth postoperative days.

\section{Criteria of assessment}

- Pain: According to visual analogue scale (VAS), all the patients was given a $10 \mathrm{~cm}$ VAS scale and instructed about the rating. They were asked to enter their level of pain at the time when analgesic is used, and the number of tablets taken till the end of the first week of extraction.

- Swelling: Facial swelling was evaluated by measuring the distance from the tragus of ear to corner of mouth and to pogonion. Second point was measured from ala of nose to the angle of the mandible.

- Trismus: For mouth opening, the subjects were asked to open the mouth slowly until the felling of first pain. At that point, the distance between the incisal edge of the mandibular and maxillary anterior teeth was measured using a measuring tape. The data were collected on printed forms and transports into Microsoft excel worksheet and data analyzed using SPSS (ver 20.0) statistical package. "P" value was set less than or equals to 0.05 as statistically significant.

\section{RESULTS}

The group I consisted of 13 (52\%) males and 11 (48\%) females. The patients were from 19-35 years of age. The group II consisted of $15(56 \%)$ males and 10 (44\%) females. The patients were from 17 to 35 year of age. In the present study it was observed that $33 \%$, $11 \%$ and $49 \%$ of the teeth were mesioangular, horizontal and distoangular respectively and all teeth were moderately difficult.

The measurements of the facial swelling in terms of horizontal and vertical components showed no statistically significant difference between the Group I and Group II. In both Group I and II, horizontal and vertical component of the facial swelling reached to peak on 2nd postoperative day and got nearly normal on 1oth day. However there was no statistically significant difference between 
the two groups on any postoperative days. (Table 1 $\& 2$ ). Pain and swelling scores were recorded on second, seventh and tenth post-operative days after surgery. The pain was evaluated using VAS scale on

\begin{tabular}{|c|c|c|c|c|c|c|}
\hline & Group & $\mathbf{N}$ & Mean & $\begin{array}{l}\text { Std. } \\
\text { deviation }\end{array}$ & $\mathbf{t}$ & P value \\
\hline \multirow[t]{2}{*}{ HR Pre-op } & I & 25 & 11.02 & 0.726 & \multirow[t]{2}{*}{-2.358} & \multirow[t]{2}{*}{$0.02^{*}$} \\
\hline & II & 25 & 11.36 & 0.706 & & \\
\hline \multirow[t]{2}{*}{ HR $2^{\text {nd }}$ day } & I & 25 & 11.77 & 0.765 & \multirow[t]{2}{*}{-0.289} & \multirow[t]{2}{*}{$0.773^{\#}$} \\
\hline & II & 25 & 11.72 & 0.687 & & \\
\hline \multirow[t]{2}{*}{$\mathrm{HR} 7^{\text {th }}$ day } & I & 25 & 11.40 & $0.75^{8}$ & \multirow[t]{2}{*}{-0.526} & \multirow[t]{2}{*}{$0.600^{\#}$} \\
\hline & II & 25 & 11.48 & 0.683 & & \\
\hline \multirow[t]{2}{*}{ HR $10^{\text {th }}$ day } & I & 25 & 11.17 & 0.707 & \multirow{2}{*}{-1.333} & \multirow[t]{2}{*}{$0.186^{\#}$} \\
\hline & II & 25 & 11.36 & 0.702 & & \\
\hline
\end{tabular}

Table 1. Horizontal measurement of face

\begin{tabular}{|c|c|c|c|c|c|c|}
\hline & Group & $\mathbf{N}$ & Mean & $\begin{array}{l}\text { Std. } \\
\text { deviation }\end{array}$ & $\mathbf{t}$ & $P$ value \\
\hline \multirow[t]{2}{*}{ VR Pre-op } & I & 25 & 9.89 & 0.658 & \multirow[t]{2}{*}{-2.588} & \multirow[t]{2}{*}{$0.011^{*}$} \\
\hline & II & 25 & 10.23 & 0.646 & & \\
\hline \multirow{2}{*}{ VR $2^{\text {nd }}$ day } & I & 25 & 10.56 & 0.684 & \multirow[t]{2}{*}{0.302} & \multirow[t]{2}{*}{$0.763^{\#}$} \\
\hline & II & 25 & 10.52 & 0.637 & & \\
\hline \multirow[t]{2}{*}{ VR $7^{\text {th }}$ day } & I & 25 & 10.19 & 0.725 & \multirow[t]{2}{*}{-1.161} & \multirow[t]{2}{*}{$0.248^{\#}$} \\
\hline & II & 25 & 10.35 & 0.631 & & \\
\hline \multirow[t]{2}{*}{ VR $10^{\text {th }}$ day } & I & 25 & 9.95 & 0.636 & \multirow[t]{2}{*}{-1.355} & \multirow[t]{2}{*}{$0.179^{\#}$} \\
\hline & II & 25 & 10.25 & 0.674 & & \\
\hline
\end{tabular}

Table 2. Vertical measurement of face

the second, seventh and tenth postoperative day. The difference in pain scores on second post-operative day between two group were found statistically non-significant, however, there were significant reduction in pain scores on seventh and tenth day in both groups. None of the patient in either of the group needed rescue NSAIDs or opioid analgesics during the postoperative period. There was statistically significant difference in the severity of pain between the two groups. The $p$ value was $<0.001$ on each postoperative day. Maximum pain was observed on second postoperative day. No significant difference was observed between the groups with respect to decrease pain by the time. Intensity of pain was greater in group I patient on all postoperative day. (Table 3)

Mouth opening showed statistically significant difference between the two groups. The $p$ value on each postoperative day was <0.oo1. In both the groups, the results showed reduced mouth opening on the second postoperative day with a 
mean value of $9.56+0.684 \mathrm{~mm}$ in first group and $09.52 \pm 0.637 \mathrm{~mm}$ in second group and a gradual increase in mouth opening thereafter. The Group I got normal mouth opening on $7^{\text {th }}$ day whereas

\begin{tabular}{|c|c|c|c|c|c|c|}
\hline & Group & $\mathbf{N}$ & Mean & Std. dev. & $\mathbf{t}$ & P value \\
\hline \multirow[t]{2}{*}{ Pain $2^{\text {nd }}$ day } & I & 25 & 5.84 & 0.817 & \multirow[t]{2}{*}{12.10} & \multirow[t]{2}{*}{$0.061^{\#}$} \\
\hline & II & 25 & 3.60 & 1.049 & & \\
\hline \multirow[t]{2}{*}{ Pain $7^{\text {th }}$ day } & I & 25 & 3.02 & 0.958 & \multirow[t]{2}{*}{8.45} & \multirow[t]{2}{*}{$<0.001^{* *}$} \\
\hline & II & 25 & 1.30 & 1.073 & & \\
\hline \multirow[t]{2}{*}{ Pain $10^{\text {th }}$ day } & I & 25 & 1.12 & 1.023 & \multirow[t]{2}{*}{$5 \cdot 33$} & \multirow[t]{2}{*}{$<0.001^{* *}$} \\
\hline & II & 25 & 0.22 & 0.615 & & \\
\hline
\end{tabular}

Table 3. Measurement of Pain score using Visual Analogue Scale

\begin{tabular}{|c|c|c|c|c|c|c|}
\hline & Group & $\mathbf{N}$ & Mean & Std. dev. & $\mathrm{T}$ & P value \\
\hline \multirow[t]{2}{*}{ Mmo Pre-op } & I & 25 & 9.89 & 0.658 & \multirow[t]{2}{*}{-2.418} & \multirow[t]{2}{*}{$<0.001^{* *}$} \\
\hline & II & 25 & 10.23 & 0.646 & & \\
\hline \multirow[t]{2}{*}{ Mmo VR $2^{\text {nd }}$ day } & I & 25 & $9 \cdot 56$ & 0.684 & \multirow[t]{2}{*}{0.302} & \multirow[t]{2}{*}{$<0.001^{* *}$} \\
\hline & II & 25 & $9 \cdot 5^{2}$ & 0.637 & & \\
\hline \multirow[t]{2}{*}{ Mmo VR $7^{\text {th }}$ day } & I & 25 & 10.09 & 0.725 & \multirow[t]{2}{*}{-1.161} & \multirow[t]{2}{*}{$<0.001^{* *}$} \\
\hline & II & 25 & 10.35 & 0.631 & & \\
\hline \multirow[t]{2}{*}{ Mmo $1^{\text {th }}$ day } & I & 25 & 10.05 & 0.636 & \multirow[t]{2}{*}{-1.355} & \multirow[t]{2}{*}{$<0.001^{* *}$} \\
\hline & II & 25 & 10.30 & 0.637 & & \\
\hline
\end{tabular}

Table 4. Maximum Mouth Opening [**Highly Significant $(\mathrm{p}<0.001)$ ]

Group II achieved on 1oth day. (Table 4). No systemic or local complications were observed with preoperative dexamethasone injection in any of the patient. Risk of local infection, alveolar osteitis was not observed in group II as compared to group I. Healing process was traced by long term follow ups of the both groups and observed no statistically significant change between the groups.

\section{DISCUSSION}

Non Steroidal Anti-Inflammatory Drugs are the oldest and most widely used drugs in history of extraction of teeth. However, no single NSAIDs is universally effective or tolerated. ${ }^{15}$ Need for better pain relief measure is of paramount importance for the clinician as well as the patient as pain during or after treatment can cause serious consequences including physiological complications, psychological impairments and overall affect the quality of life.

Dexamethasone is a most potent, highly selective, long acting synthetic corticosteroid which has an anti-inflammatory action. ${ }^{13}$ It has been used by oral surgeons since 1965 in an attempt to reduce pain and swelling following surgery. Messer and Keller used patients as their own controls and concluded that thirty percent reduction in pain in the Dexamethasone group when assessed 48 hours post-operatively. Direct application of the steroid in the traumatized tissues may thus reduce the inflammation related events. ${ }^{16}$

Studies by Hooley JR et al. ${ }^{17}$ and Skjelbred P et al. ${ }^{13}$ showed that pain was significantly reduced due to use of prophylactic steroid administration. Also, Dexamethasone in particular appears to diminish pain after surgery. ${ }^{18}$

Use of corticosteroids to limit postoperative edema due to their suppressive action on transudation is a well known argument made by many authors but few have suggested definitive recommendations supported by randomised clinical trials. ${ }^{12}$

A study conducted by Baxendale BR et al. on Dexamethasone for reduction of swelling following extraction of third molar teeth concluded that, Dexamethasone group had more patients with mild swelling and very few patients 
with severe swelling. ${ }^{19}$

Another study was conducted by Elhag M et al. for establishing anti-inflammatory effects of Dexamethasone. $^{20}$ It was observed that Dexamethasone group had mean swelling volumes significantly lesser $(\mathrm{P}<0.05)$ than their controls but at such high dose of $10 \mathrm{mg}$, incidence of hypothalamic-pituitary-adrenal axis suppression was increased, as demonstrated by marked reduction in plasma cortisol in Dexamethasone group. Using the patients as their own controls, Messer and Keller concluded that there is a considerable reduction in swelling in Dexamethasone group in comparison with patients who did not administered Dexamethasone. ${ }^{16}$

Graziani $\mathrm{F}$ et al. reported that Dexamethasone significantly decrease facial swelling especially on second post-operative day when maximum facial swelling is expected. Also with increase in dosage from $4 \mathrm{mg}$ to $10 \mathrm{mg}$ of Dexamethasone, a greater reduction in swelling was observed. ${ }^{21}$

The facial size should reach the pre-operative facial measurement by seventh day, nine percent increment from the pre-operative measurement was observed. This was in agreement with various studies conducted by Bamgbose $\mathrm{B} \mathrm{O}$ et al. ${ }^{22}$, Baxendale B R et al. ${ }^{19}$, Graziani F et al. ${ }^{21}$ and Anne Pedersen $^{23}$ but contrary to the above mentioned studies and the present study, Neupert EA et al. ${ }^{24}$ and Edilby GI et al. ${ }^{25}$ found that there was no significant reduction in swelling between Dexamethasone and control groups.

\section{CONCLUSION}

The study finding indicates the efficacy and safety of submucosal administration of dexamethasone injection during third molar extraction to eliminate or reduce post operative pain, swelling and trismus. The observations of the present study provide a fundamental basis for the use of corticosteroids such as dexamethasone sodium phosphate in the form of submucosal administration in lower than usual doses to decrease postoperative inflammation when compare to other routes of drug administration. Administration of low dose Dexamethasone around the extraction site has a more desirable effect due to more drug concentration at the site of injury for a long time without loss due to distribution in system. Moreover, when surgical removal of the third molar is done under local anesthesia, it is very convenient for both patient and oral surgeon to use the submucosal site for effective administration of drug. Group randomisation, single examiner, regular follow-up to achieve the objectives of the study is the advantages but minimum sample size and lack of blinding procedure are some of the limitation of the study. In future, role of other corticosteroids such as methyl prednisolone, application of local drug delivery methods, optimum dose of steroid, histological \& radiographic comparison of the wound healing can be done.

\section{REFERENCES}

1. Kumar VR, Yadav P, Kahsu E, Girkar F, Chakraborty R. Prevalence and Pattern of Mandibular Third Molar Impaction in Eritrean Population: A Retrospective Study. J Contemp Dent Pract 2017;18(2):100-6.

2. Palma C, Coelho A, González Y, Cahuana A. Failure of eruption of first and second permanent molars. The Journal of Clinical Pediatric Dentistry 2003; 27(3):239-46.

3. Subbaiah MT, Ponnuswamy IA, David MP. Relationship between mandibular angle fracture and state of eruption of mandibular third molar: A digital radiographic study. J Indian Acad Oral Med Radiol. 2015;27:35-41.

4. Jadhao VA, Rao A, Hande P, Mahajani M, Raktade PP, Gedam R et al. The Efficiency of Three Irrigating Solutions after Surgical Removal of Impacted Mandibular Third Molars: A Crosssectional Study. The Journal of Contemporary Dental Practice 2018;19(9):1147-51.

5. Murugesan K, Sreekumar K, Sabapathy B. Comparison of the roles of serratiopeptidase and dexamethasone in the control of inflammation and trismus following impacted third molar surgery. Indian J Dent Res 2012;23:709-13.

6. Simoneti LF, Weckwerth GM, Dionísio TJ, Torres EA, Zupelari-Gonçalves P, Calvo AM et al. Efficacy of Ketoprofen With or Without Omeprazole for Pain And Inflammation Control After Third Molar Removal. Brazilian Dental Journal 2018;29(2):140-9.

7. Beeman CS. Third molar management: a case for routine removal in adolescent and young adult orthodontic patients. J Oral Maxillofac Surg 1999;57(7):824-30. 
8. Berge TI, Boe OE. Predictor evaluation of postoperative morbidity after surgical removal of mandibular third molars. Acta Odontol Scand 1994;52(3):162-9.

9. Conrad SM, Blakey GH, Shugars DA, Marciani RD, Phillips C, White RP. Patients' perception of recovery after third molar surgery. J Oral Maxillofac Surg 1999;57(11):1288-94.

10. Earl P. Patients' anxieties with third molar surgery. Br J Oral Maxillofac Surg 1994;32(5):293-

7 .

11. Grossi GB, Maiorana C, Garramone AR. Assessing postoperative discomfort after third molar surgery: A prospective study. J Oral Maxillofac Surg 2007;65:901.

12. Alexander RE, Throndson RR. A review of perioperative corticosteroid use in dentoalveolar surgery. Oral Surg Oral Med Oral Pathol Oral Radiol Endod 2000;90(4):406-15.

13. Skjelbred P, Lokken P. Post-operative pain and inflammatory reaction reduced by injection of a corticosteroid. A controlled trial in bilateral oral surgery. Eur J Clin Pharmacol 1982;21(5):391-6.

14. Bystedt $H$, Nordenram A. Effect of methylprednisolone on complications after removal of impacted mandibular third molars. Swed Dent J 1985;9(2):65-9.

15. Savin J, Ogden GR. Third molar surgery-A preliminary report on aspects affecting quality of life in the early postoperative period. $\mathrm{Br} \mathrm{J}$ Oral Maxillofac Surg 1997;35:246.

16. Messer EJ, Keller JJ. The use of intraoral Dexamethasone after extraction of mandibular third molars. Oral Surg Oral Med Oral Pathol 1975;40(5):594.

17. Hooley JR, Bradley PB, Haines MP. Plasma cortisol levels following short-term betamethasone therapy for oral surgical procedures Trans. 4th ICOMS. Copenhagen (Denmark): Munksgaard; 1973.

18. Shah SA, Khan I, Shah HS. Effectiveness of Submucosal Dexamethasone to Control Postoperative Pain \& Swelling in Apicectomy of Maxillary Anterior Teeth. Int J Health Sci (Qassim) 2011;5(2):156-165.

19. Baxendale BR, Vater $M$, Lavery KM. Dexamethasone reduces pain and swelling following extraction of third molar teeth. Anaesthesia 1993;48:961-4.

20. Elhag M, Coghlan K, Christmas P, Harvey W, Harris M. The anti-inflammatory effects of
Dexamethasone and therapeutic Ultrasound in oral surgery. Br J Oral Maxillofac Surg 1985;23:1723.

21. Graziani F, D'Aiuto F, Arduino PG, Tonelli M, Gabriele M. Peri-operative Dexamethasone reduces post-surgical sequelae of wisdom tooth removal. A split-mouth randomized doublemasked clinical trial. Int J Oral Maxillofac Surg 2006; 35(3):241-6.

22. Bamgbose BO, Akinwande JA, Adeyemo WL, Ladeinde AL, Arotiba GT, Ogunlewe MO. Effects of co-administered Dexamethasone and Diclofenac potassium on pain, swelling and trismus following third molar surgery. Head \& Face Medicine 2005;1:11.

23. Pedersen A. Decadronphosphate in the relief of complaints after third molar surgery A doubleblind, controlled trial with bilateral oral surgery. Int. J. Oral Surg 1985;14:235-40.

24. Neupert EA, Lee JW, Philput GB, Gordon JR. Evaluation of dexamethasone for reduction of post surgical sequelae of third molar removal. J Oral Maxillofac Surg 1992;50:1177-83.

25. Edilby GI, Gennitt SP. A double blind Placebo controlled trial on the effect of Dexamethasone as post-operative swelling. J Dent Res 1982;62:556. 
Cite this article as:

Ahmed N, Yadav OP, Asopa SP, Panwar M, Khan A, Buri M. Efficacy of Pre-Operative Submucosal Injection of Dexamethasone in Mandibular Third Molar Surgery: A Randomized

Source of support: Nil, Conflict of interest: None declared

\section{AUTHOR AFFILIATIONS:}

1. Senior Resident, Dental Department, Sardar Patel Medical College \& Associated Group of Hospital, Bikaner

2. Research Scientist (Medical), Department of Clinical Microbiology \& Immunology, Sardar Patel Medical College \& Associated Group of Hospital, Bikner

3. $\quad$ Reader, Department of Prosthodontics, Rajasthan Dental College and Hospital, Jaipur

4. $\quad$ PG Student, Department of Public Health Dentistry, Rajasthan Dental College and Hospital, Jaipur

5. $\quad$ Research Assistant, Rajasthan University of Health Sciences, Jaipur

6. Private Dental Practitioner, Barala Hospital, Jaipur

\section{*Corresponding Author:}

Dr. Omprakash Yadav

Research Scientist (Medical)

A-44, Ashok Nagar

Purani Chungi, Ajmer Road

Jaipur, Rajasthan
For article enquiry/author contact details, e-mail at: editor.ihri@gmail.com,editor@ihrjournal.com 